\title{
BACTERIAS HALOTOLERANTES CON ACTIVIDAD LIPOLÍTICA AISLADAS DE LAS SALINAS DE PILLUANA SAN MARTÍN
}

\author{
Halotolerant bacteria with lipolytic activity isolated from Pilluana Salterns - San Martin \\ Mónica L. Flores-Fernández, Amparo I. Zavaleta, Elizabeth L. Chávez-Hidalgo \\ Laboratorio de Biología Molecular, Facultad de Farmacia y Bioquímica \\ Universidad Nacional Mayor de San Marcos
}

\section{RESUMEN}

Con el objetivo de aislar bacterias halotolerantes con actividad lipolítica de las Salinas de Pilluana - San Martín, se recolectaron muestras de suelos salinos y se sembraron en agar agua de sales al $5 \%$ conteniendo extracto de levadura 0,5\%. Se preseleccionaron 55 bacterias con características morfológicas diferentes, sembrándose simultáneamente en agar agua de sales al $5 \%$ conteniendo tributirina, Tween 80 y aceite de oliva al $1 \%$. En base a la capacidad de hidrolizar los sustratos específicos y presentar tolerancia salina variable desde 0 hasta $25 \%$, se seleccionaron 14 bacterias que crecieron óptimamente a $37^{\circ} \mathrm{C}$ y pH 7 , seis fueron bacilos Gram positivos y ocho Gram negativos; 12 de las bacterias hidrolizaron tributirina, Tween 80 y aceite de oliva; seis produjeron amilasas y proteasas. Las 14 bacterias halotolerantes con actividad lipolítica aisladas de las Salinas de Pilluana constituyen fuentes promisorias para la producción de lipasas y biotratamiento de residuos oleosos.

Palabras clave: Bacterias halotolerantes, bacterias lipolíticas, suelos salinos, Salinas de Pilluana.

\section{SUMMARY}

In order to isolate halotolerant bacteria with lipolytic activity from the Pilluana Salterns in San Martin, saline soil samples were collected and cultured in $5 \%$ salt water agar containing $0,5 \%$ yeast extract. It was pre-selected 55 bacteria with different morphological characteristics, these bacteria were grown simultaneously in $5 \%$ salt water agar containing $1 \%$ tributyrin, Tween 80 and olive oil. It was selected 14 bacteria based on the ability to hydrolyze specific substrates and shown high salt tolerance rate between 0 to $25 \%$. These bacteria grew optimally at $\mathrm{pH} 7$ and $37^{\circ} \mathrm{C}$, six were Gram positive and Gram negative eight, 12 bacteria hydrolyzed tributyrin, Tween 80 and olive oil, six produced amylases and proteases. The 14 halotolerant bacteria with lipolytic activity isolated from the Pilluana salterns are promising lipase production sources and oily waste bio-treatment.

Keywords: Halotolerant bacteria, lipolytic bacteria, salty soil, Pilluana Salterns.

\section{INTRODUCCIÓN}

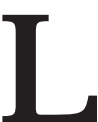

as bacterias halotolerantes son microorganismos capaces de vivir tanto en ausencia como en presencia de sales, habitan ambientes salinos de diversas zonas geográficas cuya composición iónica es variable. Así, se aislaron bacterias Gram negativas y positivas pertenecientes a los géneros Pseudomonas y Bacillus, respectivamente, como productoras de lipasas extracelulares disponibles en el mercado ${ }^{(1,2)}$.

Las bacterias halotolerantes poseen múltiples aplicaciones biotecnológicas en la producción de enzimas, aminoácidos, exopolisacáridos, entre otros. No obstante, la producción de enzimas es el área más promisoria de todas, pues estas bacterias poseen características como estabilidad a altas concentraciones Salinas, versatilidad de uso y bajo riesgo de contaminación durante su cultivo, que en conjunto favorecen su escalamiento a nivel industrial ${ }^{(3)}$.

Los suelos contienen la mayor biodiversidad microbiana del planeta; sin embargo existen pocas investigaciones que hayan estudiado el potencial biotecnológico de las bacterias halotolerantes aisladas de suelos hipersalinos. En este contexto las Salinas de Pilluana por presentar clima tropical se constituyen como una fuente promisoria potencial para estudios sobre aprovechamiento de la biodiversidad bacteriana. Por ello, en esta investigación se aislaron y caracterizaron bacterias halotolerantes con actividad lipolítica mediante técnicas bacteriológicas. 


\section{MATERIAL Y MÉTODOS}

\section{Toma de muestras}

Se recolectaron muestras de suelos en cinco puntos geográficos de las Salinas de Pilluana, provincia de Picota (San Martín); luego se transportaron en frío hasta el momento de su inoculación, que se efectuó dentro de las 48 horas después del muestreo.

\section{Aislamiento}

Se resuspendió $1 \mathrm{~g}$ de suelo en $10 \mathrm{~mL}$ de buffer fosfato salino estéril, luego se realizaron diluciones seriadas al décimo desde $10^{-1}$ hasta $10^{-6}$ y se sembraron por duplicado $100 \mu$ de cada una de las diluciones sobre el agar agua de sales al $5 \%$. Se seleccionaron las colonias que presentaron características morfológicas diferentes entre sí y para garantizar la pureza de los aislados se realizaron tres siembras sucesivas. Posteriormente, se evaluó la actividad hidrolítica sobre tributirina, Tween 80 y aceite de oliva al $1 \%$ teniendo como base agar agua de sales al $5 \%$; se preseleccionaron a los aislados que hidrolizaron por lo menos a uno de los tres sustratos.

\section{Características morfológicas}

Para identificar estas características se siguió la técnica de Gram convencional utilizando cultivos frescos de $20 \mathrm{~h}^{(4)}$.

\section{Pruebas fisiológicas}

Para evaluar la tolerancia salina, los microorganismos se inocularon en agua de sales, con extracto de levadura al 0,5\%, a concentraciones de $0 ; 2,5 ; 5,0 ; 10,0$ y $25,0 \%$, y se incubaron a $37^{\circ} \mathrm{C}$ por $24 \mathrm{~h}$. Para determinar el pH óptimo de crecimiento se utilizó caldo tripticasa de soya a pH de cinco a nueve, y se incubó a $37^{\circ} \mathrm{C}$ por 24 horas. La temperatura óptima se determinó inoculando los aislados en el caldo antes descrito a $20 ; 37$ y $42{ }^{\circ} \mathrm{C}$. Para los tres casos el crecimiento bacteriano se determinó por espectrofotometría a $600 \mathrm{ym}$.

\section{Pruebas bioquímicas}

Se realizaron las pruebas de oxidasa, catalasa, producción de sulfuros, indol, movilidad y oxidación o fermentación de glucosa. En la preparación de los medios se utilizó agua de sales al $5 \%$ y medios base específicos como SIM y O/F según indicaciones de Hugh y Leifson ${ }^{(5)}$.

\section{Actividad hidrolítica a diversos sustratos}

Almidón. La actividad amilolítica se determinó por el método de Cowan y Steel's que utiliza agar almidón (DIFCO) conteniendo sales al 5\% y $\mathrm{pH} 7,4$. Los microorganismos se incubaron a $37{ }^{\circ} \mathrm{C}$ durante dos días y se añadió $10 \mathrm{~mL}$ de lugol sobre las placas. Se consideró reacción positiva cuando la formación de un halo claro alrededor de las colonias productoras de amilasas ${ }^{(6)}$.

Caseína. La capacidad de hidrolizar caseína se determinó por el método de Collins ${ }^{(7)}$. Al agar caseína se añadió sales al $5 \%$ y se incubó a $37^{\circ} \mathrm{C}$ durante $72 \mathrm{~h}$. La reacción se consideró positiva cuando alrededor de la colonia se formó un halo por efecto de la proteólisis.

Gelatina. Se determinó usando el agar gelatina nutritiva (DIFCO) con agua de sales al $5 \%$, las bacterias crecieron a $37{ }^{\circ} \mathrm{C}$ por $24 \mathrm{~h}$, después se guardó a $4{ }^{\circ} \mathrm{C}$ por $15 \mathrm{~min}$. La reacción se considero positiva cuando se evidenció licuefacción del medio.

\section{RESULTADOS}

\section{Aislamiento y selección de bacterias halotolerantes con actividad lipolítica}

De los suelos de las Salinas de Pilluana se aislaron 55 bacterias por presentar diferentes características morfológicas. Después, se seleccionaron 33 microorganismos que presentaron actividad lipolítica variable sobre los sustratos tributirina, Tween 80 y aceite de oliva. De los 33 aislados, sólo 14 crecieron en medios de cultivo con y sin sales, demostrando su halotolerancia. Las 14 bacterias seleccionadas presentaron colonias con características diversas tales como: consistencia gomosa, forma redonda o amorfa y la mayoría fueron de color crema. Con respecto a las características microscópicas se observó bacilos, ocho Gram negativos y seis Gram positivos (tabla 1).

\section{Características fisiológicas, bioquímicas y nutricionales}

Se determinó que 12 de las 14 bacterias halotolerantes crecieron entre o a $25 \%$ de sales; siendo las concentraciones más frecuentes 5,0 y $7,5 \%$. Además, se determinó que las bacterias crecen entre 20 y $42{ }^{\circ} \mathrm{C}$, a pH de cinco a ocho, siendo los óptimos $37^{\circ} \mathrm{C}$ y pH 7. Todos los aislados fueron móviles y catalasa positivos; la mayoría 
Tabla 1. Características fenotípicas de las bacterias halotolerantes productoras de lipasas extracelulares aisladas de las Salinas de Pilluana - San Martín

\begin{tabular}{|c|c|c|c|c|c|c|c|c|c|c|c|c|c|c|c|}
\hline & Aislado & T-1 & T-2 & T-3 & T-4 & T-5 & T-6 & T-7 & T-8 & T-9 & T-10 & T-11 & T-12 & T-13 & T-14 \\
\hline \multirow{4}{*}{$\begin{array}{l}\frac{\pi}{0} \\
0 \\
0 \\
0 \\
0 \\
\vdots \\
\vdots \\
\Sigma\end{array}$} & $\begin{array}{l}\text { Morfología } \\
\text { celular }\end{array}$ & Bacilo & $\begin{array}{l}\text { Bacilo } \\
\text { corto }\end{array}$ & $\begin{array}{l}\text { Bacilo } \\
\text { corto }\end{array}$ & Bacilo & Bacilo & Bacilo & Bacilo & Bacilo & Bacilo & Bacilo & Bacilo & Bacilo & Bacilo & Bacilo \\
\hline & Tinción Gram & - & - & - & - & - & - & + & + & + & - & - & + & + & + \\
\hline & Pigmentación & Crema & Crema & Crema & Crema & Crema & Naranja & Crema & Crema & Crema & Crema & Crema & Crema & Crema & Rosada \\
\hline & $\begin{array}{l}\text { Morfología } \\
\text { colonia }\end{array}$ & Redonda & Redonda & Redonda & Redonda & Redonda & Amorfa & Redonda & Amorfa & Redonda & Redonda & Redonda & Redonda & Amorfa & Redonda \\
\hline \multirow{3}{*}{$\begin{array}{l}\frac{\pi}{0} \\
0 \\
0 \\
0 \\
0 \\
0 \\
0\end{array}$} & $\begin{array}{l}\text { \% de sales } \\
\text { óptimo }\end{array}$ & 7,5 & 5,0 & 5,0 & 12,5 & 7,5 & 10,0 & 10,0 & 5,0 & 2,5 & 5,0 & 12,5 & 7,5 & 2,5 & 5,0 \\
\hline & pH óptimo & 7 & 7 & 7 & 7 & 7 & 7 & 7 & 7 & 7 & 7 & 7 & 7 & 7 & 7 \\
\hline & $\begin{array}{l}\text { Temperatura } \\
\text { óptima }\left({ }^{\circ} \mathrm{C}\right)\end{array}$ & 37 & 37 & 37 & 37 & 37 & 37 & 37 & 37 & 37 & 37 & 37 & 37 & 37 & 37 \\
\hline$\pi$ & Catalasa & + & + & + & + & + & + & + & + & + & + & + & + & + & + \\
\hline \multirow{5}{*}{$\begin{array}{l}u \\
= \\
\Xi \\
= \\
z \\
\sigma \\
0 \\
= \\
-\end{array}$} & Oxidasa & - & - & - & - & - & - & + & - & + & - & + & - & + & + \\
\hline & Motilidad & + & + & + & + & + & + & + & + & + & + & + & + & + & + \\
\hline & $\begin{array}{l}\text { Producción de } \\
\text { indol }\end{array}$ & - & - & - & - & - & - & + & - & - & - & - & - & - & - \\
\hline & $\begin{array}{l}\text { Producción de } \\
\text { sulfuros }\end{array}$ & - & - & - & - & - & + & - & - & + & - & - & - & + & + \\
\hline & $\begin{array}{l}\text { Oxidación / } \\
\text { Fermentación } \\
\text { de glucosa }\end{array}$ & $\mathrm{F}$ & $\mathrm{F}$ & $\mathrm{F}$ & $\mathrm{F}$ & $\mathrm{F}$ & $\mathrm{F}$ & $\mathrm{F}$ & $\mathrm{F}$ & 0 & $\mathrm{~F}$ & 0 & $\mathrm{~F}$ & 0 & $\mathrm{~F}$ \\
\hline \multirow{6}{*}{ 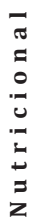 } & Tributirina & 1 & 1 & 1 & 1 & 1 & 2 & 2 & 2 & 1 & 2 & 3 & 3 & 1 & 2 \\
\hline & Tween 80 & 2 & 1 & 1 & 1 & 1 & 3 & 1 & 3 & 1 & 2 & 3 & 1 & 1 & 1 \\
\hline & Aceite de Oliva & 1 & 0 & 0 & 2 & 1 & 2 & 1 & 3 & 1 & 1 & 3 & 2 & 1 & 1 \\
\hline & Caseína & 0 & 0 & 0 & 0 & 0 & 0 & 1 & 1 & 2 & 0 & 1 & 1 & 1 & 1 \\
\hline & Gelatina & 2 & 1 & 1 & 2 & 1 & 0 & 3 & 2 & 1 & 1 & 2 & 1 & 1 & 1 \\
\hline & Almidón & 0 & 0 & 0 & 0 & 0 & 0 & 2 & 2 & 1 & 1 & 2 & 1 & 2 & 0 \\
\hline
\end{tabular}

Ensayo: +, positivo; -, negativo; $\mathbf{O}$, oxidación; $\mathbf{F}$, fermentación.

Tamaño de halo de hidrólisis (mm): $\mathbf{0}$, ninguna; $\mathbf{1}, 1-3 ; \mathbf{2}, 4-8 ; \mathbf{3}, \geq 9$

fermentan a la glucosa, no producen sulfuros ni indol (tabla 1).

\section{Características nutricionales}

Los aislados seleccionados presentaron diferentes perfiles hidrolíticos respecto a almidón, caseína y gelatina; seis hidrolizan los tres sustratos, cinco no hidrolizan almidón ni caseína; y un aislado no hidrolizó ninguno de los sustratos analizados (tabla 1).

\section{DISCUSIÓN}

Los ambientes hipersalinos presentan microorganismos adaptados a condiciones adversas de $\mathrm{pH}$, temperatura, concentración salina y composición iónica. Así, las 14 bacterias halotolerantes aisladas de las Salinas de Pilluana presentan diferente grado de tolerancia salina óptima, lo cual les confiere ventajas para su uso en la producción de metabolitos o enzimas; y en biotratamiento.

Todos los aislados resultaron ser bacilos: seis Gram positivos y ocho Gram negativos, en este aspecto Ventosa y col, describieron que la mayoría de las bacterias ambientales capaces de producir enzimas hidrolíticas son Gram negativas pertenecientes a los géneros Halomonas y Salinivibrio ${ }^{(8)}$; similares resultados reportaron Yeon y col, quienes estudiaron la diversidad bacteriana de las Salinas de Korea, donde de las 64 bacterias aisladas, 45 pertenecían a los géneros Halomonas y Salinivibrio. En referencia a los microorganismos Gram positivos, estos autores determinaron que los géneros más representativos en ambientes hipersalinos son Bacillus y Virgibacillus ${ }^{(9)}$.

Con respecto a las características fisiológicas, se determinó que los aislados son alcalomesófilos, resultado concordante con antecedentes que han descrito la existencia de microorganismos de habitats tropicales pertenecientes a esta categoría $(10,11)$. La concentración salina óptima estuvo entre 5 , 0 y $7,5 \%$ para ocho de los aislados; datos que 
difieren de los obtenidos por Larsen y Kushner ${ }^{(12,13)}$, quienes han descrito que la concentración óptima de sal para la mayoría de bacterias halotolerantes es de $8 \%$ de $\mathrm{NaCl}$; no obstante, ambos autores opinan que la concentración salina óptima depende del tipo de medio y temperatura de crecimiento de las bacterias.

En el presente estudio se observó que 12 de los aislados fueron capaces de tolerar concentraciones Salinas entre o y $25 \%$, por lo que en su mayoría podrían ser consideradas bacterias halotolerantes extremas. Al respecto, recientes investigaciones como la realizada por Mata y col. (14), describen especies halotolerantes asociadas al género Halomonas. Las características bioquímicas de los aislados fueron variadas; sin embargo, los resultados obtenidos en los ensayos de motilidad y producción de catalasa fueron positivos para todos. Los aislados T-7, T-9, T-13 y T-14 fueron positivos para la prueba de oxidasa. Considerando los antecedentes bibliográficos y similitud de las características fenotípicas antes mencionadas, se puede inferir que los cuatro aislados pertenecen a la familia Bacillaceae, que incluye a miembros de los géneros Bacillus y Virgibacillus ${ }^{(9)}$.

La capacidad hidrolítica de los aislados $\mathrm{T}-7, \mathrm{~T}-8, \mathrm{~T}-9, \mathrm{~T}-11, \mathrm{~T}-12$ y $\mathrm{T}-13$ a sustratos específicos como almidón, caseína y gelatina permiten considerarlos como reservorios de enzimas hidrolíticas. En la actualidad, los estudios realizados por Stosz y Garabito $(15,16)$ han descrito la producción de enzimas hidrolíticas extracelulares a partir de bacterias halotolerantes. Estas investigaciones responden de manera general al creciente interés de la industria biotecnológica por desarrollar procesos tecnológicos exigentes y limpios utilizando microorganismos o sus enzimas. En este aspecto, las bacterias halotolerantes se adaptan a las exigencias del mercado por su versatilidad para adaptarse a medios con y sin sal.

\section{CONCLUSIONES}

Se aislaron e identificaron 14 bacterias halotolerantes con actividad lipolítica provenientes de suelos de las Salinas de Pilluana, provincia de Picota (San Martín), las cuales constituyen fuentes promisorias para la producción de lipasas, así como para el tratamiento de residuos oleosos.

AGRADECIMIENTOS. Este estudio fue financiado parcialmente por los contratos VRI 090403012 y 017 / FINCYT/PIBAP/2008.

\section{REFERENCIAS BIBLIOGRÁFICAS}

1. Kushner DJ. Life in high salt and solute concentrations: Halophilic bacteria. En: Microbial Life in Extreme Environments. Londres: Academic Press: 1978. p. 318-46.

2. Ventosa A, Nieto JJ. Biotechnological applications and potentialities of halophilic microorganisms. World J Microbiol Biotechnol 1995; 11(1): 85-94.

3. Rohit S, Yusuf Ch, Uttam Ch. Production, purification, characterization, and applications of lipases. Biotech Adv 2001; 19: 627- 62.

4. Jenkins D, Richard MG, Daigger GT. Manual on the causes and control of activated sludge bulking and foaming. 2a ed. Nueva York: Lewis Publishers; 1993: p.193.

5. Hugh R, Leifson E. The taxonomic significance of fermentative versus oxidative metabolism of carbohydrates by various gram-negative bacteria. J Bacteriol. 1953; 66: 24-26.

6. Cowan ST, Steel LJ. Manual for the Identification of Medical Bacteria, zera ed. UK: Cambridge University Press, 1993.

7. Collins $\mathrm{CH}$, Lyne PM. Métodos microbiológicos. Editorial Acribia; Zaragoza: 1989.

8. Ventosa A. Taxonomy of moderately halophilic eubacteria. En: Halophilic bacteria. Boca Raton Press; Florida, 1988: p. 71-84.

9. Yeon S, Jeong WJ, Park JS. The diversity of culturable organotrophic bacteria from local solar salterns. J Microbiol 2005; 43:1-10.

10. Sylian J, Rodríguez P, Bishop L. Three-dimensional quantification of soil biofilms using image analysis. En: Environ Engin Science. Mary Ann Liebert, Inc; New York, 2007: p. 96-103.

11. Kai $U$ et al. Biogeochemical interfaces in soil: The interdisciplinary challenge for soil science. J Plant Nutr Soil Sci 2010; 173(1): 88-99.

12. Larsen H. Halophilic and halotolerant microorganisms an overview and historical perspective. FEMS Microbiol Ecol 1986; 39(1-2): 3-7.

13. Kushner DJ. Halophilic bacteria: life in and out of salt. En: Recent advances in microbial ecology. Tokyo: Japan Scientific Societies Press; 1989: p. 6o-4.

14. Mata JA, Martinez-Canovas MJ, Quesada E, Béjar VA. 
Detalied phenotypic characterization of the type strains of Halomonas species. Syst Appl Microbiol 2002; 25: 360-75.

15. Stosz S, Weiner R, Coyne V. Agarase system from Alteromonas strain 2-40. Patent US5418156. 1995.

16. Garabito MJ, Márquez MC, Ventosa A. Halotolerant Bacillus diversity in hypersaline environments. Can J Microbiol 1998; 44: 95-102.
Manuscrito recibido el: 31/o1/2011

Aceptado para su publicación el: 18/02/2011

\section{Correspondencia:}

Nombre: Amparo Zavaleta Pesantes

Dirección: Jr. Puno 1002 - Lima 1 - Peru.

e-mail: azavaletap@unmsm.edu.pe 